\title{
CARACTERIZAÇÃO DA POLPA DE ABACATE (Persea americana MILL) DA REGIÃO DO ALTO PARANAÍBA
}

\section{CHARACTERIZATION OF AVOCADO PULP (Persea americana MILL) OF THE ALTO PARANAÍBA REGION}

\author{
A. P. OLIVEIRA ${ }^{1}$; I. C. GUIMARÃES ${ }^{1}$; E. G. T. MENEZES ${ }^{1}$ \\ ${ }^{1}$ Instituto de Ciências Agrárias. Universidade Federal de Viçosa - Campus Rio Paranaíba \\ E-mail: amanda.p.oliveira@ufv.br
}

\author{
$\underline{\text { article info }}$ \\ Article history: \\ Received 12 May 2017 \\ Accepted 3 August 2017 \\ Available online 20 September 2017
}

PALAVRAS-CHAVE: Abacate; Caracterização; Óleo.

\author{
KEYWORDS: Avocado; Description; Oil.
}

\begin{abstract}
RESUMO: $O$ abacate (Persea americana Mill) é um fruto originado do continente Americano, amplamente produzido no território brasileiro. A polpa carnuda do abacate proporciona um óleo de alta qualidade, apresentando diversos compostos bioativos. Neste trabalho, realizou-se um estudo para caracterização do abacate proveniente da região do Alto Paranaíba. Inicialmente, a polpa do abacate foi seca em estufa e moída. O farelo obtido após a moagem foi caracterizado por métodos físico-químicos, através da determinação do teor de umidade, proteínas, lipídeos, cinzas e carboidratos. Para a análise de carotenoide foi utilizado abacate in natura. Os resultados demonstraram que a polpa de abacate possui elevadas concentrações de óleo $(47,26 \%$ em base seca) e carotenoides (13,04 mg/lo0g de polpa em base úmida), podendo assim a polpa ser utilizada para extração de óleo destinado às indústrias farmacêuticas elou alimentícias.
\end{abstract}

ABSTRACT: Avocado (Persea americana Mill) is a fruit originated from the American continent, widely produced in Brazilian territory. The fleshy pulp of avocado provides a high quality oil, featuring various bioactive compounds. In this work, a study was carried out to characterize the avocado from the Alto Paranaíba region. Initially, the avocado pulp was oven dried and ground. The bran obtained after milling was characterized by physicochemical methods, through the determination of moisture content, proteins, lipids, ashes and carbohydrates. For carotenoid analysis, avocado in natura was used. The results showed that avocado pulp has high concentrations of oil (47.26\% on dry basis) and carotenoids (13.04 mg / $100 \mathrm{~g}$ of wet pulp), so that the pulp can be used for oil extraction for Pharmaceutical and/or food industries.

\section{INTRODUÇÃO}

O abacate (Persea americana Mill) é um fruto originado do continente Americano, amplamente produzido no território brasileiro. Apresenta um grande número de variedades, incluindo Fortuna, Quintal, Geada, Margarida e Hass (JORGE et al., 2015).

Em 2014, o Brasil produziu aproximadamente 157,6 mil toneladas de abacate em uma área de 9,4 mil hectares. O Estado de São Paulo (79,3 milhões de frutos) e Minas Gerais (41,3 milhões de frutos) juntos tiveram a participação de $76,9 \%$ do mercado de produção. No 


\section{The Journal of Engineering and Exact Sciences - \\ JCEC \\ ISSN: 2527-1075}

mesmo ano, a região do Alto Paranaíba foi responsável por 30,36\% da produção do estado de Minas Gerais, com uma produção de cerca de 12.530 toneladas de abacate (FAO, 2016).

Consumidos in natura ou utilizados na indústria de alimentos ou cosméticos, os frutos originados do abacateiro, possuem como principal característica um elevado teor de óleo, em sua polpa, que varia de acordo com as cultivares, localização do pomar, e tempo de colheita. Desta forma, a extração do óleo da polpa é uma opção viável, visto que possui utilização em indústrias alimentícias ou farmacêuticas, devido as suas propriedades nutricionais (OLIVEIRA et al., 2013; DREHER; DAVENPORT, 2013; SANTANA et al., 2015). Sua polpa carnuda favorece óleo de alta qualidade com altas quantidades de ácido oleico, se assemelhando às propriedades físico-químicas do azeite de oliva (TANGO; CARVALHO; SOARES, 2004; QUIÑNONES-ISLAS et al., 2013). O óleo de abacate apresenta diversos compostos bioativos, possuindo carotenoides, ácido ascórbico, compostos fenólicos, tocoferóis, fitoesterois, entre outros (SANTOS et al., 2014; LOZANO et al., 1993; SALGADO et al., 2008).

O objetivo deste trabalho foi caracterizar polpas de abacates obtidos na Região do Alto Paranaíba- Minas Gerais. A partir dos resultados obtidos podemos mostrar a viabilidade da utilização de polpa de abacate para extração de óleo.

\section{MATERIAL E MÉTODOS}

Foram utilizados abacates (Persea americana Mill) obtidos no município de Rio Paranaíba-MG. Inicialmente os frutos maduros foram higienizados (solução de hipoclorito, $200 \mathrm{mg} / \mathrm{kg}$ ) e despolpados manualmente. As polpas, então, foram armazenadas congeladas ($18{ }^{\circ} \mathrm{C}$ ) até o momento do seu uso. Antes da caracterização e processos de extrações, as polpas foram secas em estufa a vácuo sob temperatura de $60^{\circ} \mathrm{C}$, durante $48 \mathrm{~h}$ (pressão absoluta $=$ 16,8 kPa; Tecnal, modelo TE-395, Piracicaba, SP, Brasil). Posteriormente, as mesmas foram trituradas em liquidificador industrial (Camargo, Itajobi, SP, Brasil).

Determinação das percentagens das porções polpa, casca e caroço

Foram determinadas, em três abacates, as percentagens de polpa, casca e caroço em relação à massa total dos frutos.

Composição química da polpa de abacate

Os teores de umidades, cinzas, proteínas e lipídeos foram determinados por metodologias padrões propostos pela AOAC (ASSOCIATION OF OFICIAL ANALYTICAL CHEMISTRAL, 2005).

O óleo esterificado foi analisado por cromatografia gasosa, de acordo com o método oficial 1-62 da AOCS (AMERICAN OIL CHEMISTS SOCIETY, 1998), em cromatógrafo Shimadzu QP 210, com detector de ionização em chama (FID), utilizando coluna capilar 0,2 um X 100 m X 0,25 mm (SP-2560, Sulpeco, Bellefonte, PA, USA). 


\section{The Journal of Engineering and Exact Sciences - \\ JCEC \\ ISSN: 2527-1075}

A identificação dos ácidos graxos foi feita por comparação dos tempos de retenção dos ésteres contidos no padrão Supelco 37 FAME MIX com os da amostra. A quantificação dos ácidos graxos foi realizada por normalização interna da área do pico.

\section{Carotenoides}

Os carotenoides presentes na polpa de abacate foram extraídos e quantificados de acordo com o método proposto por Rodriguez-Amaya (2001). Essa análise foi realizada em base úmida.

\section{RESULTADOS E DISCUSSÃO}

O conteúdo de polpa variou entre 73,89 e 79,11\% em relação à massa do fruto. Em estudo de Tango (2004) a variedade de abacate Quintal apresentou 81,3\% de polpa, enquanto que a variedade de abacate Mac Donald que apresentava menor quantidade de polpa 52,9\%.

O teor de umidade foi de 75,96\%, valor este que se adequa aos encontrados por Tango (2004) que ao avaliar diversas variedades de abacate encontrou um teor de umidade que variou entre 57,2 e 87,9\%. O valor de umidade encontrado, mostrou-se superior ao de Salgado (2008) que encontrou 58,35\% na variedade Margarida A composição centesimal em base seca do abacate é apresentada na Tabela 1.

O teor de extrato etéreo foi superior ao encontrado por Tango (2004) que encontrou valores entre 5,3 e 31,1\% e por Lucchesi (1975) que ao avaliar abacates de variedades diferentes de 3 cidades de São Paulo, em seu período ápice de extração de óleo, encontrou valores entre 15,83 a $22,02 \%$.

Tabela 1 - Caracterização centesimal de abacate

\begin{tabular}{cc}
\hline & Composição Centesimal (\%) \\
\hline Extrato etéreo & $47,26 \pm 0,14$ \\
Proteína & $4,93 \pm 0,22$ \\
Cinzas & $3,76 \pm 0,12$ \\
Carboidratos & 44,05 \\
\hline
\end{tabular}

$\mathrm{O}$ alto teor de óleo encontrado nas polpas dos abacates mostra a possibilidade em sua extração, visto que este denota cada vez mais importância na indústria de cosméticos, farmacêutica e alimentícia, pois diminui a tensão superficial dos líquidos, possui elevadas quantidade de vitaminas lipossolúveis, alto poder de penetração, além de odor leve e pouca rancificação (HAENDLER,1970).

O teor de proteínas, cinzas e carboidratos, em base úmida, encontrado por Salgado et al. (2008) na variedade Margarida foi 2,54\%, 0,60\% e 7,25\% respectivamente.

Com relação aos carotenoides, foram quantificados os $\beta$-carotenos e licopenos, que apresentaram-se nas concentrações de $8,05+0,25 \mathrm{mg} / 100 \mathrm{~g}$ de polpa úmida e 4,99+0,27 $\mathrm{mg} / 100 \mathrm{~g}$ de polpa úmida, respectivamente. Segundo Zeraik (2008) o $\beta$-caroteno é um 


\section{The Journal of Engineering and Exact Sciences - \\ JCEC \\ ISSN: 2527-1075}

carotenoide que possui ação antioxidante devido às suas ligações duplas conjugadas, que são suscetíveis à oxidação sob ação de luz ou oxigênio. Já o licopeno, possui maior reatividade, provavelmente devido à presença de duas ligações duplas não conjugadas, lhe conferindo maior capacidade sequestrante de oxigênio molecular (KRINSKY, 2003).

As composições de ácidos graxos, presentes nas frações lipídicas da polpa de abacate, são apresentadas na Tabela 2

A maioria dos ácidos graxos, presentes na polpa de abacate, apresentam cadeias insaturadas $(74,89 \%)$, sendo os mais encontrados em ordem decrescente o ácido oleico $(52,13 \%)$, ácido palmítico $(22,72 \%)$ e ácido linoleico (14,78 \%)

O ácido oleico foi o ácido graxo mais encontrado na polpa de abacate. Existem evidencias de que o ácido oleico apresenta um papel importante na inibição da proliferação de células tumorais, em virtude de sua capacidade em suprimir a expressão do HER2 (erbB-2), um oncogene bem conhecido por seu envolvimento na etiologia, progressão e metástase do câncer (CARRILLO; CAVIA; ALONSO-TORRE, 2012).

Tabela 2 - Composição de ácidos graxos presentes na polpa de abacate

\begin{tabular}{cccc}
\hline Nomenclatura & $\mathrm{CCx}: \mathrm{y}$ & $\begin{array}{c}\mathrm{MM} \\
(\mathrm{g} / \mathrm{mol})\end{array}$ & Abacate $*(\%)$ \\
\hline Ácido palmítico & $\mathrm{C} 16: 0$ & 256,43 & $22,72 \pm 0,09$ \\
Ácido palmitoleico & $\mathrm{C} 16: 1$ & 254,41 & $7,14 \pm 0,03$ \\
Ácido esteárico & $\mathrm{C} 18: 0$ & 284,49 & $1,96 \pm 0,05$ \\
Ácido oleico & $\mathrm{C} 18: 1$ & 282,47 & $52,13 \pm 0,15$ \\
Ácido linoleico & $\mathrm{C} 18: 2$ & 280,45 & $14,78 \pm 0,04$ \\
Ácido linolênico & $\mathrm{C} 18: 3$ & 278,44 & $0,84 \pm 0,01$ \\
Ácido araquídico & $\mathrm{C} 20: 0$ & 315,54 & $0,11 \pm 0,01$ \\
Ácido behênico & $\mathrm{C} 22: 0$ & 340,59 & $0,32 \pm 0,02$ \\
\hline
\end{tabular}

*Resultados expressos pela média e desvio padrão

O ácido palmítico (C 16:0) foi o ácido graxo de cadeia saturada mais encontrado na polpa de abacate. De acordo com Luzia e Jorge (2013), o ácido palmítico é o ácido de cadeia saturado mais encontrado em óleos vegetais.

\section{CONCLUSÕES}

O abacate apresenta potencial nutricional, com alto teor de lipídeos, podendo ser utilizado para fabricação de diversos produtos, tanto para indústria alimentícia, farmacêutica e de cosméticos, contribuindo com a economia da região. Estudos posteriores com o objetivo de extrair o óleo de abacate foram realizados a fim de otimizar sua extração.

\section{AGRADECIMENTOS}

CNPq/PIBIC que possibilitaram a realização deste trabalho. 


\section{REFERÊNCIAS}

AMERICAN OIL CHEMISTS' SOCIETY. Official methods and recommended pratices of the American Oil Chemists'Society. 3. ed. Champaingn: American Oil Chemists' Society, 1998. $1410 \mathrm{p}$.

ASSOCIATION OF OFICIAL ANALYTICAL CHEMISTRAL. Official methods of analysis of the association of official analytical chemistry. 17. ed. Washington: AOAC, 2005. $1410 \mathrm{p}$.

CARAMORI, S. S.; LIMA, C. S.; FERNANDES, K. F. Biochemical characterization of selected plant species from Brazilian savannas. Brazilian Archives of Biology and Technology, Curitiba, v. 47, n. 2, p. 253-259, jun. 2004.

DREHER, M. L.; DAVENPORT, A. J. Hass Avocado Composition and Potential Health Effects. Critical Reviews in Food Science and Nutrition, v. 53, n. 7, p. 738- 750, 2013.

FAO. Food and Agriculture organization and the United Nations. Production / Live Animals. 2016. Disponível em: <http://faostat3.fao.org/browse/home/E>. Acesso em: 20/03/2017.

HAENDLER, L. Journee d'information sur l'huile d'avocat. Fruits. v.25, n.12, p.911-914, 1970.

JORGE, T. D. S. et al. Physicochemical And Rheological Characterization Of Avocado Oils. Ciencia e Agrotecnologia, v. 39, n. 4, p. 390-400, 2015.

LOZANO, Y. F. et al. Unsaponifiable Matter, Total Sterol And Tocopherol Contents Of Avocado Oil Varieties. Journal of the American Oil Chemists Society, v. 70, n. 6, p. 561-565, 1993.

LUCCHESI, A.A., MONTENEGRO, H.W.S. Influencia ecológica no desenvolvimento do fruto e no teor de óleo na polpa do abacate (Persea americana Miller). Anais da Esc. Sup. Agric. "Luiz de Queiroz", vol. 32, p. 419-447. 1975

LUZIA, D. M. M.; JORGE, N. Bioactive substance contents and antioxidant capacity of the lipid fraction of Annona crassiflora Mart. seeds. Industrial Crops and Products, Amsterdam, v. 42, p. 231-235, Mar. 2013.

OLIVEIRA, M. C. et al. Phenology and physical and chemical characterization of avocado fruits for oil extraction. Ciência Rural, v. 43, n. 3, p. 411-418, 2013.

OLIVEIRA, V.S., Influência do processamento em ultrassom do licopeno e vitamina $\mathbf{E}$ e B. Dissertação (Mestrado em Engenharia Química). Universidade Federal do Ceará, p.102. 2014.

QUINONES-ISLAS, N. et al. Detection of adulterants in avocado oil by Mid-FTIR spectroscopy and multivariate analysis. Food Research International, v. 51, n. 1, p. 148-154, 2013.

RODRIGUEZ-AMAYA, B. B. A guide to carotenoid analysis in foods. Washington: ILST Press, 2001. $71 \mathrm{p}$.

SALGADO, J. M. et al. The avocado oil (Persea americana Mill) as a raw material for the food industry. Ciência e Tecnologia de Alimentos, v. 28, p. 20-26, 2008.

SANTANA, I. et al. Avocado (Persea americana Mill.) oil produced by microwave drying and expeller pressing exhibits low acidity and high oxidative stability. European Journal of Lipid Science and Technology, v. 117, n. 7, p. 999-1007, 2015. 
ISSN: 2527-1075

SANTOS, M. A. Z. et al. Profile of Bioactive Compounds in Avocado Pulp Oil: Influence of the Drying Processes and Extraction Methods. Journal of the American Oil Chemists Society, v. 91, n. 1, p. 19-27, 2014.

TANGO, J.S.; CARVALHO, C.R.L.; SOARES,N.B. Caracterização física e química de frutos de abacate visando o seu potencial extração de óleo. Revista Brasileira de Fruticultura, v.17, n.1, p.17-23, 2004. 